\title{
Hospital admissions of adults with community-acquired pneumonia in Portugal between 2000 and 2009
}

\author{
Filipe Froes*, António Diniz*, Margarida Mesquita*, \\ Margarida Serrado* and Baltazar Nunes"
}

ABSTRACT: Recent studies in the USA and northern Europe have shown an increase in community-acquired pneumonia (CAP). In southern Europe, this increase has not yet been documented.

We carried out a retrospective analysis from encoded information from the Portuguese database for hospital admissions that included all individuals aged $\geqslant 18$ years, with a primary diagnosis of pneumonia, who were discharged between 2000 and 2009. We excluded patients infected with HIV, individuals immunocompromised as a result of anti-cancer or immunosuppressive treatment, and transplant recipients.

Of the 294027 admissions for CAP, 56\% were male. The mean age was 73.1 years and the median age 77 years. Between 2000 and 2009, there was a 5\% increase in the average age of patients admitted with CAP.

Admissions for CAP represented $3.7 \%$ of total admissions of adult patients. The average annual rate of hospital admissions for adults with CAP was 3.61 per 1000 total population, rising to 13.4 for those aged $\geqslant 65$ years. Between 2000-2004 and 2005-2009 the average annual rate of hospital admission for CAP per 1000 population increased by $28.2 \%$.

Hospital admissions for CAP in Portugal increased between 2000 and 2009. It has grown consistently over time, varying according to age with males over-represented.

KEYWORDS: Community-acquired pneumonia, incidence, pneumonia

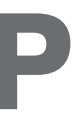
rospective studies prior to 1987 in the USA and in northern European countries estimated an annual rate of between five and 11 cases of community-acquired pneumonia (CAP) per 1000 adult population [1-3].

The percentage of adults having to be hospitalised with CAP was very variable. Depending on the country or region analysed, the length of the study and the period in which it took place, there were differences in the population studied and the organisation of the health systems, in addition to climatic variation and the annual and seasonal changes of circulating microorganisms (e.g. Mycoplasma pneumoniae and respiratory virus).

Data published in the USA and Canada before 2000 documented global annual rates of adult hospital admissions with CAP of between 1.1 and four cases per 1000 inhabitants [4, 5], which increased to 13.2 cases per 1000 inhabitants among those aged $>55$ years [6]. In the USA [7] and the countries of northern Europe, such as the UK [8], Denmark [9] and the Netherlands [10], recent studies have shown a steady increase in the number of hospital admissions for pneumonia. In the UK, between 1997-1998 and 20042005 , there was an increase of $34 \%$ in the annual average rate of admission of patients with a primary diagnosis of pneumonia [8].

In Portugal, a southern European country, data relating to 1998-2000 show that adult admission with CAP was $2.9 \%$ of the total hospital admissions for all causes [11]. During this period, there was an average annual rate of hospitalisation of 2.66 per 1000 population $\geqslant 15$ years of age and 9.78 per 1000 for the group aged $\geqslant 65$ years. The average age for patient admission was 69.8 years [11]. This study aims to characterise the incidence of adult admission with CAP between the years 2000 and 2009, and to analyse its evolution over these 10 years.

\section{METHODS}

The Central Administration of the Health System of the Portuguese Ministry of Health contains administrative and clinical data of all admissions
AFFILIATIONS

*Serviço de Pneumologia II, Hospital de Pulido Valente, Centro Hospitalar Lisboa Norte, Lisbon,

"Centro de Saúde de Ourém, ACES Serra D'Aire, Ourém, and

"Departamento de Epidemiologia, Instituto Nacional de Saúde Dr. Ricardo Jorge, Lisbon, Portugal.

CORRESPONDENCE

F. Froes

Serviço de Pneumologia II Hospital de Pulido Valente Centro Hospitalar Lisboa Norte Alameda das Linhas de Torres 117 1769-001 Lisbon Portugal

E-mail: filipe.froes@gmail.com

Received:

Dec 102011

Accepted after revision: July 202012

First published online: Aug 092012 
to National Health hospitals, which covers almost the whole resident population of mainland Portugal. The clinical information, including diagnoses and procedures, is encoded from the details of the hospital discharge report by medical staff who have been specially trained in hospital coding, using the International Classification of Diseases, 9th Revision Clinical Modification (ICD-9-CM) [12].

In this study, we analysed retrospectively the hospital admissions of adults with a primary discharge diagnosis of pneumonia (ICD-9-CM 480-486 and 487.0) who were discharged between 2000 and 2009. Patients under 18 years of age and those in whom pneumonia was not the main diagnosis were excluded. As ICD-9-CM does not specify whether pneumonia is community acquired, we also excluded patients with HIV (ICD-9-CM 042-044 and/or diagnosis-related groups 488,489 and 490), individuals who were immunocompromised by anti-cancer or immunosuppressive treatment (external cause of disease code E933.1) and transplant recipients (V42). The analysis of clinical information maintained patient anonymity.

The size of the population of mainland Portugal was obtained from the information line of the National Institute of Statistics [13] and corresponds to the estimates of the resident population at the end of the year, subdivided by age and sex, for each year of the study.

To obtain the relevant indicators for this study, we adopted a descriptive statistical analysis approach having calculated the following: Rates of admission for CAP per 1000 population, percentage of admissions for CAP from total admissions for all diagnoses, proportional distribution of admissions by age group and sex and, finally, average and median ages of CAP admissions.

All the calculations presented were obtained using the statistical software package STATA (release 11; StataCorp, College Station, TX, USA) and the Microsoft Excel spreadsheet (Microsoft Corp., Redmond, WA, USA).

\section{RESULTS}

\section{Patient characteristics}

A total of 294027 admissions for CAP were included in the study for the 10-year period between 2000 and 2009. Of this total, $56 \%$ were males and $44 \%$ females. The median age was 77 years and the mean \pm SD age was $73.1 \pm 16.0$ years, with a median age of 75 years and mean \pm SD age of $71.3 \pm 15.9$ years for males and a median age of 79 years and an mean \pm SD age of $75.3 \pm 15.7$ years for females. The greatest age was 109 years for females and 111 years for males. During the course of the study, we observed a consistent increase in the annual average age of patients of both sexes (fig. 1).

In the older patient age groups, aged $75-84$ and $\geqslant 85$ years, there was an increase in the average age. From 2000 to 2009, the average age increased by 0.45 and 0.46 years for patients aged $75-84$ and $\geqslant 85$ years, respectively.

Out of a total 294027 patients studied, 10.3\% were between 18 and 49 years of age, $11.9 \%$ between 50 and 64 years, 19.5\% between 65 and 74 years, 34.7\% between 75 and 84 years, and $23.6 \%$ aged $\geqslant 85$ years.

\section{Admissions for CAP per total admissions}

In mainland Portugal, between 2000 and 2009, a total of 7849266 hospital admissions occurred. Of this total, 294027 $(3.7 \%)$ were diagnosed with pneumonia and, according to the criteria for inclusion of this study, were considered to have CAP. The proportion of CAP admissions was greater in the older age groups, constituting $5.5 \%$ of those aged $\geqslant 50$ years, $7.0 \%$ of those aged $\geqslant 65$ years, $9.4 \%$ of those aged $\geqslant 75$ years and $13.8 \%$ of those aged $\geqslant 85$ years. For patients under the ages of 50 and 65 years, the percentages of admissions for CAP were $1.0 \%$ and $1.4 \%$, respectively.

Between the periods 2000-2004 and 2005-2009 there was an increased rate of admission for CAP in all age groups; this was independent of sex but more marked in patients aged $>65$ years (table 1 ).

Throughout the 10 years of the study, we observed an increase in the percentage of admissions for CAP in the total admissions; this was particularly marked in the older age groups (fig. 2).

Incidence of admissions for CAP per 1000 total population Between 2000 and 2009, there was an average annual incidence of 3.61 admissions of adults with CAP per 1000 population. Between the age groups of $<50$ and $\geqslant 50$ years the incidence increased from 0.66 to 7.49 . In the age groups $<65$ and $\geqslant 65$ years, the incidence increased from 1.02 to 13.40 . From 2000 to 2009, the incidence of admission per 1000 population went up $55.6 \%$, from 3.02 to 4.70 and, in the 5-year periods 2000-2004 and 2005-2009, it increased by $28.2 \%$. With the exception of the 18-29-year-old subjects, this increase was progressive year on year for all the other age groups (table 2).

If we exclude the year 2009 from the analysis, because of the influenza pandemic, we can see that the increase in hospital admissions per 1000 population during the periods 2000-2004 and 2005-2008 was 23.5\%; this increase was observed only in the age groups aged $\geqslant 50$ years.

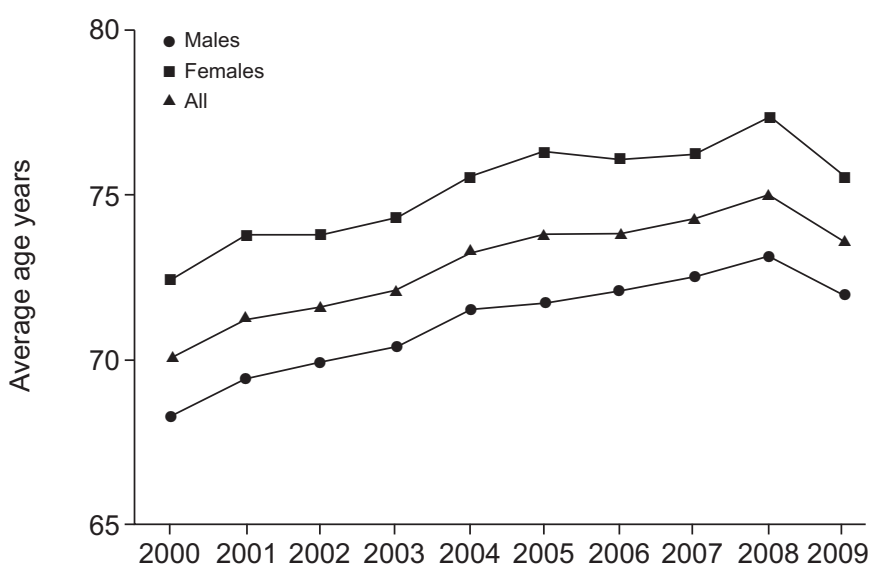

Age years

$\begin{array}{lllllllllll}\text { Males } & 68.3 & 69.4 & 69.9 & 70.4 & 71.5 & 71.7 & 72.1 & 72.5 & 73.1 & 72.0\end{array}$

$\begin{array}{lllllllllll}\text { Females } & 72.4 & 73.8 & 73.8 & 74.3 & 75.5 & 76.3 & 76.1 & 76.2 & 77.3 & 75.5\end{array}$

$\begin{array}{lllllllllll}\text { All } & 70.1 & 71.3 & 71.6 & 72.1 & 73.3 & 73.8 & 73.8 & 74.2 & 75.0 & 73.6\end{array}$

FIGURE 1. Evolution of the average age of adult admissions for communityacquired pneumonia by sex and year between 2000 and 2009 in mainland Portugal. 


\begin{tabular}{|c|c|c|c|c|c|c|c|c|}
\hline & \multirow[t]{2}{*}{ Period } & \multicolumn{7}{|c|}{ Age group years \% } \\
\hline & & $18-29$ & $30-49$ & $50-64$ & $65-74$ & $75-84$ & $>85$ & Overall \\
\hline Males & 2000-2004 & 1.3 & 2.2 & 2.7 & 4.4 & 8.1 & 14.6 & 4.4 \\
\hline \multirow[t]{3}{*}{ Females } & 2000-2004 & 0.3 & 0.6 & 1.6 & 3.2 & 5.9 & 11.0 & 2.5 \\
\hline & 2005-2009 & 0.4 & 0.7 & 1.7 & 3.5 & 7.1 & 13.5 & 3.3 \\
\hline & 2000-2009 & 0.4 & 0.6 & 1.7 & 3.3 & 6.6 & 12.5 & 2.9 \\
\hline \multirow[t]{2}{*}{ Overall } & 2000-2004 & 0.6 & 1.2 & 2.2 & 3.8 & 7.0 & 12.3 & 3.3 \\
\hline & 2005-2009 & 0.6 & 1.3 & 2.3 & 4.2 & 8.3 & 15.0 & 4.2 \\
\hline
\end{tabular}

The average global admission incidence for CAP was higher for males than females, at 4.21 and 3.07, respectively, per 1000 population (table 2). In those aged $>50$ years, this figure increased to 9.14 for males and 6.14 for females. For those aged $>65$ years, it grew to 16.73 for males and 10.64 for females.

Over the 10 years it can be observed that the annual increase in CAP admissions per 1000 population was most noticeable in the group aged $\geqslant 75$ years (fig. 3 ).

\section{DISCUSSION}

The Portuguese Ministry of Health database is essentially administrative. The clinical information is coded from discharge documents; this work is carried out exclusively by medical doctors who have been formally trained in hospital coding to make the process more rigorous. The Ministry of Health carries out regular audits, both internally and externally, of this coding process.

In this study, to exclude patients with complications from nosocomial pneumonia, only those cases with a primary discharge diagnosis of pneumonia were analysed. However, it is likely that some cases of nosocomial pneumonia may have

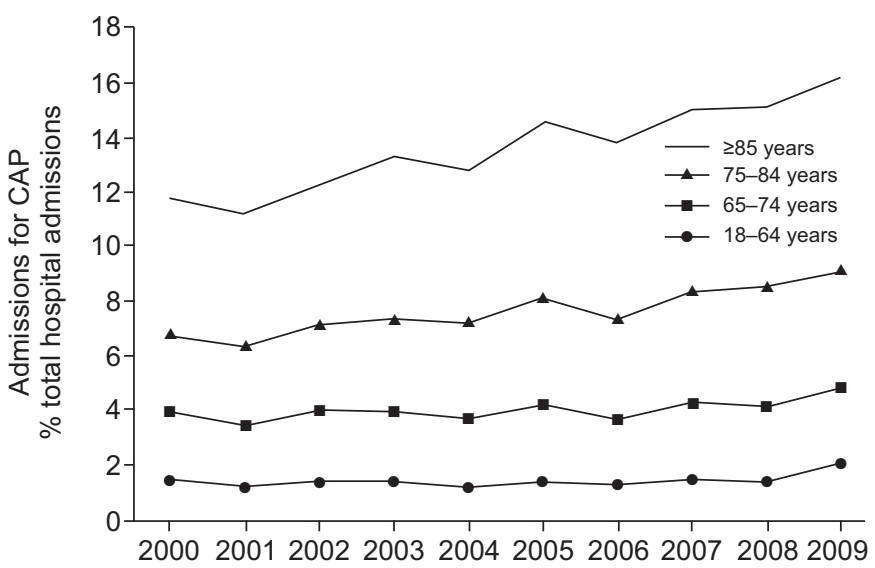

FIGURE 2. Evolution of the annual percentage of admissions for communityacquired pneumonia (CAP) out the total adult admissions by age group between 2000 and 2009 in mainland Portugal. been included due to coding error or because the database did not allow for the identification of patients re-admitted soon after a recent discharge from hospital. Patients living in nursing homes or in institutions for long-term care could not be identified from the database so it is likely that cases of pneumonia have been included that are healthcare related, particularly among the elderly. However, this concept and its inclusion in nosocomial pneumonia is not universally agreed on and for some authors would not be valid for Europe [14]. The fact that hospitalisation is more accessible and the reluctance to let patients die at home without support may explain the inclusion in the study of elderly patients with endof-life pneumonia.

In this study, the information about the length of stay in hospital, which could have helped to make the methodology more specific, was not measured [15]. Likewise, there were no data available relating to the vaccination status of hospitalised patients, and it was also not possible to evaluate the impact of comorbidities in hospital admissions. The exclusion of patients infected with HIV, transplant recipients and those admitted for causes external to the disease, such as anticancer treatment or immunosuppressors, could have increased the accuracy of identification of admissions with CAP.

Apart from these limitations, the methodologies are similar to those that have been used in other countries $[6,8,11,16]$. One advantage of this study is that it covers a period of 10 years, a fact that can minimise the impact of years that deviate from the norm, such as 2009 when the influenza pandemic H1N1 occurred. Official data in Portugal estimate that, in 2009 and 2010, 2400 patients were admitted to hospital as a result of the influenza pandemic A(H1N1) 2009 [17]. Our analysis does not cover the year 2010, and it was not possible to separate out the admissions due to the pandemic that occurred in 2009 from those that occurred in 2010 [17]. It is possible that hospital admissions for the A (H1N1) pandemic could represent up to $0.8 \%$ of the total admissions on our database and $6.2 \%$ of the admissions in 2009. We do not have information on the average age of patients admitted, but official data document that the 124 deaths caused by the pandemic correspond to a mortality rate of 1.17 deaths per 100000 population, with an average age at death of 47.6 years [18]. According to these data, 


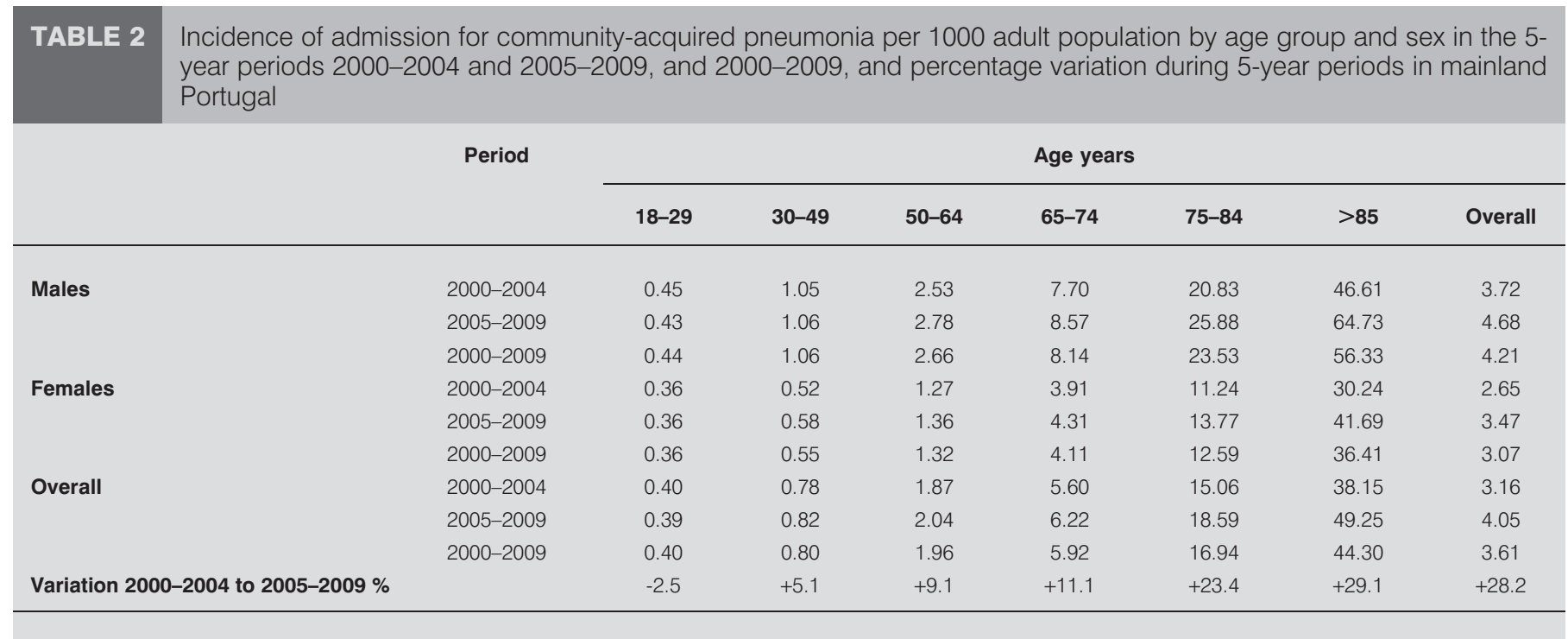

it is possible that the influenza pandemic could have had an impact on the increased numbers of hospital admissions that occurred in 2009, particularly in the groups aged $<50$ years.

In the period from 2000 to 2009, the average age of patients admitted for CAP and the median age were, respectively, 73.1 and 77 years (71.3 and 75 years for males and 75.3 and 79 years for females). The reduction in the average age of patients admitted in 2009 (fig. 1) could have been related to the influenza pandemic. The age factor is patently clear: $89.7 \%$ of admissions were aged $\geqslant 50$ years, $77.8 \%$ were $\geqslant 65$ years, $58.3 \%$ were $\geqslant 75$ years and $23.6 \%$ were $\geqslant 85$ years.

These data are very similar to those that EwIG et al. [19] found in Germany between 2005 and 2006. In our study, we also confirmed the impact of age on the increase in admissions for CAP. The average age grew from 70.1 years in 2000 to 73.6 years in 2009, which corresponds to an increase of $5.0 \%$ in the average age over a decade. This increase is greater than the increase in average life expectancy in Portugal, which, between 2000 and 2009, changed from 73 to 76 years for males

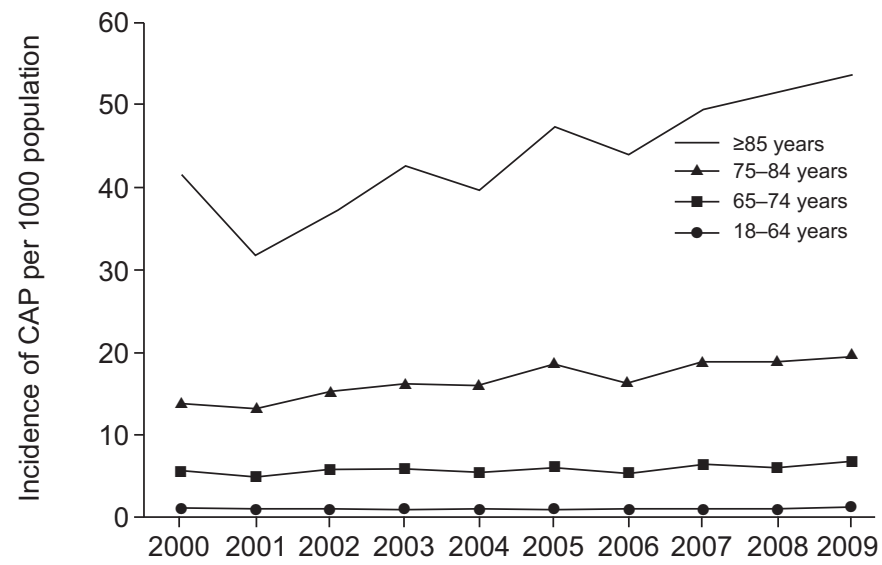

FIGURE 3. Evolution of the annual incidence of admission for communityacquired pneumonia (CAP) per 1000 population by age group between 2000 and 2009 in mainland Portugal. and from 80 to 82 years for females [20]. The half-year increase in the average age of the older patients, i.e. those aged between 75 and 84 years and $\geqslant 85$ years, between 2000 and 2009, could be one of the contributing factors to the increased numbers of admissions among these age groups.

As recorded in other recent publications [16, 19, 21] more males (56\%) were admitted to hospital than females (44\%); the percentages are similar to those in Germany [19].

Between 2000 and 2009, the total number of episodes of hospital admissions for all causes was relatively stable, varying by $3.3 \%$ between the two 5-year periods of 2000-2004 and 2005-2009. Admission for CAP represented $3.7 \%$ of all admissions. Between 2000 and 2004 (3.3\%) and 2005 and 2009 $(4.2 \%)$, there was an increase of $27.3 \%$. In relation to the period 1998-2000, the increase was $27.6 \%$ [11]. These figures confirm the increase in admission for CAP in absolute and percentage numbers.

The increase in percentage of admissions for CAP is equally dependent on age, above all in those aged $>65$ years, of whom those aged $\geqslant 75$ years had the highest percentages. Admission for CAP for patients aged $\geqslant 65$ years is five times greater than for those aged $<65$ years.

For the 10 years of the study, the average annual incidence for hospital admissions for adults with CAP per 1000 population was 3.61. Analysis by age group appears to confirm the importance of age and sex. This value always increased with age, from 7.49 and 13.40 per 1000 population in the age groups $\geqslant 50$ and $\geqslant 65$ years, respectively, up to a maximum value of 44.30 for patients aged $>85$ years. In the same way, it can be seen that the incidence of admission for CAP per 1000 population for the age group $\geqslant 65$ years is 13 times greater than for the age group $<65$ years. The incidence of admissions was always greater for males than for females in all age groups.

In Portugal, the values for incidence of admission per 1000 population between 2000 and 2009 are much higher than those recorded in the period 1998 to 2000 [11]. These values are also 
higher than those found in recent studies in other countries. In Germany, in 2005 and 2006, we found an average value of 2.86 admissions per 1000 adults [19]. In Spain, from 2003 to 2007, the values were 6.27 and 10.29 per 1000 population in the age groups $\geqslant 50$ years and $\geqslant 65$ years, respectively [16], as opposed to the 7.49 and 13.40 per 1000 population in our study. In England, in 2004-2005, the age-standardised incidence of hospital admissions with a primary diagnosis of pneumonia was 22.18 per 1000 population in the age group $\geqslant 85$ years [8]. Even allowing for differences in methodology, given the significant contrast with the figures for Portugal for the $\geqslant 85$ years age group ( 44.30 versus 22.18 ), the implication of these figures about the impact of pneumonias at end-of-life in our series must be investigated.

With the exception of the age group 18-29 years, in the rest of the age groups there has been a progressive increase in the incidence of admission for CAP per 1000 population between the 5-year periods of 2000-2004 and 2005-2009, with a global increase of $28.2 \%$. If we exclude the year 2009 from our analysis, because of the influenza pandemic, the incidence of hospital admissions per 1000 population increased by $23.5 \%$ in the periods 2000-2004 and 2005-2008 and this increase is only in the groups aged $\geqslant 50$ years. Excluding the year 2009 confirms that the steady increase of admissions per 1000 population preceded the influenza pandemic and suggests that the pandemic had impacted on the increased of hospital admissions in the groups aged $<50$ years.

The percentage of increase of hospital admissions per 1000 population in Portugal is lower than that found in England (34\% between 1997 and 1998 and between 2004 and 2005) in an age-standardised study that did not exclude patients who were immunocompromised and did include paediatric patients [8].

In Portugal, there has been a steady increase in the proportion of hospital admissions for CAP. This variation has been growing steadily over time, is increasing with age and is more marked among males. The study did not identify the causes of this increase nor explain the differences to other countries. These differences could be due to any or all of the following: an ageing population, increased comorbidities, greater ease of access to hospital services and inadequate implementation of preventive measures. In Portugal, the official data do not include information about pneumococcal vaccines and show that, in the periods from 1998 to 1999 and 2007 to 2008, the rate of coverage of the anti-flu vaccine in the population in general remained at $14.2-14.5 \%$, but increased from $31.3 \%$ to $51.0 \%$ for people aged $\geqslant 65$ years [22].

We do not know whether this increase in the hospital context is matched by an increase in the incidence of the disease in outpatients. We conclude that now is the time to obtain a more accurate characterisation of patients hospitalised and also to reevaluate the global incidence of pneumonia in the community.

\section{SUPPORT STATEMENT}

The Portuguese Pulmonology Society sponsored this study through an unrestricted educational grant from Laboratórios Pfizer SA.

\section{STATEMENT OF INTEREST}

None declared.

\section{ACKNOWLEDGEMENTS}

The authors would like to thank the ACSS/MS and, in particular, F. Cardoso and L. Faustino (ACSS, Lisbon, Portugal), for allowing us to access the database and I. Falcão (Directorate General for Health, Lisbon, Portugal) for editing.

\section{REFERENCES}

1 Woodhead MA, Macfarlane JT, McCracken JS, et al. Prospective study of the aetiology and outcome of pneumonia in the community. Lancet 1987; 1: 671-674.

2 Jokinen C, Heiskanen L, Juvonen H, et al. Incidence of communityacquired pneumonia in the population of four municipalities in eastern Finland. Am J Epidemiol 1993; 137: 977-988.

3 Foy HM, Cooney MK, Allan I, et al. Rates of pneumonia during influenza epidemics in Seattle, 1964 to 1975. JAMA 1979; 241: 253-258.

4 Marrie TJ. Epidemiology of community-acquired pneumonia in the elderly. Semin Respir Infect 1990; 5: 260-268.

5 Lave JR, Fine MJ, Sankey SS, et al. Hospitalized pneumonia. Outcomes, treatment patterns, and costs in urban and rural areas J Gen Intern Med 1996; 11: 415-421.

6 Marrie TJ, Carriere KC, Jin Y, et al. Factors associated with death among adults $<55$ years of age hospitalized for communityacquired pneumonia. Clin Infect Dis 2003; 36: 413-421.

7 Fry AM, Shay DK, Holman RC, et al. Trends in hospitalizations for pneumonia among persons aged 65 years or older in the United States, 1988-2002. JAMA 2005; 294: 2712-2719.

8 Trotter CL, Stuart JM, George R, et al. Increasing hospital admissions for pneumonia, England. Emerg Infect Dis 2008; 14: 727-733.

9 Thomsen RW, Riis A, Norgaard M, et al. Rising incidence and persistently high mortality of hospitalized pneumonia: a 10-year population-based study in Denmark. J Intern Med 2006; 259: 410-417.

10 Oosterheert JJ, Bonten MJ, Hak E, et al. Toename van pneumoniegerelateerde ziekte en sterfte onder volwassenen in Nederland en mogelijke verklaringen daarvoor. [The increase in pneumoniarelated morbidity and mortality among adults in the Netherlands and possible explanations for it.] Ned Tijdschr Geneeskd 2004; 148: 1765-1769.

11 Froes F. Community-acquired pneumonia in adults in mainland Portugal: incidence and mortality in hospital inpatients between 1998 and 2000. Rev Port Pneumol 2003; 9: 187-194.

12 International Classification of Diseases, 9th Revision - Clinical Modification. www.cdc.gov/nchs/icd/icd9.htm Date last accessed: December 11, 2012.

13 Instituto Nacional de Estatística (Statistics Portugal). Estimativas Provisórias de População Residente, Portugal, NUTS II, NUTS III e Municípios. [Provisional Estimates of Resident Population, Portugal, NUTS II, NUTS III and Municipalities.] Instituto Nacional de Estatística. www.ine.pt Date last accessed: December 10, 2012.

14 Ewig S, Welte T, Chastre J, et al. Rethinking the concept of community-acquired and health-care-associated pneumonia. Lancet Infect Dis 2010; 10: 279-287.

$15 \mathrm{Yu}$ O, Nelson JC, Bounds L, et al. Classification algorithms to improve the accuracy of identifying patients hospitalized with community-acquired pneumonia using administrative data. Epidemiol Infect 2011; 139: 1296-1306.

16 Gil-Prieto R, García-García L, Álvaro-Meca A, et al. The burden for community-acquired pneumonia (CAP) and pneumococcal pneumonia in adults in Spain (2003-2007). Vaccine 2011; 29: 412-416.

17 Direção-Geral da Saúde - Ministério da Saúde (DirectorateGeneral for Health - Ministry of Health). Relatório da Pandemia 
de Gripe em Portugal. [Report of Pandemic Influenza in Portugal.] Lisboa 2010. www.dgs.pt Date last accessed: December 10, 2012.

18 Froes F, Diniz A, Falcão I, et al. Deaths due to pandemic influenza A (H1N1) 2009 in Portugal from April 2009 to March 2010. Revista Portuguesa de Medicina Intensiva 2010; 17: 1-31.

19 Ewig S, Birkner N, Strauss R, et al. New perspectives on community-acquired pneumonia in 388406 patients. Results from a nationwide mandatory performance measurement programme in healthcare quality. Thorax 2009; 64: 1062-1069.

20 Instituto Nacional de Estatística (Statistics Portugal). Esperança de vida à nascença por Sexo e Ano. [Life expectancy at birth by sex and year.] Instituto Nacional de Estatística. www.dgs.pt Date last accessed: December 10, 2012.

21 Welte T, Torres A, Nathwani D. Clinical and economic burden of community-acquired pneumonia among adults in Europe. Thorax 2012; 67: 71-79.

22 Nunes B, Falcão JM. Vacinação antigripal: cobertura da população portuguesa entre 1998/1999 a 2007/2008. [Influenza vaccine: coverage of the Portuguese population between 1998/1999 to 2007/2008.] Instituto Nacional de Saúde Doutor Ricardo Jorge. Departamento de Epidemiologia. 2008. http://repositorio.insa.pt/ handle/10400.18/286 Date last accessed: May 11, 2012. 